\title{
MineWiki: the use of Wiki Technology as a Tool in a Senior Mine Design Course
}

\author{
Nasser Saleh \\ Integrated Learning Librarian, \\ Engineering \& Science Library \\ Queen's University \\ nasser.saleh@queensu.ca
}

\author{
Steve McKinnon \\ Professor, Department of Mining \\ Engineering \\ Queen's University \\ sm@mine.queensu.ca
}

\begin{abstract}
The paper presents an investigation of wiki technology as a teaching tool in a team mine design engineering course where students were required to develop an article on a selected design topic. The case study presents how the appropriate platform was selected through collaboration between the course instructor and the engineering librarian and the approach used in evaluating learners' experience using this technology for their first time in an academic course. The paper also reports and discusses some of the challenges that were faced during the course, in addition to the lessons learned to guide the development of the wiki for future years.
\end{abstract}

\section{Introduction}

A wiki is a web technology that allows users to easily create and edit web pages collaboratively. While the wiki was introduced many years ago with the popular example of Wikipedia, its use is relatively new in academia with very few studies available to guide the integration of wiki technology as a new learning environment in engineering design education. In a design course, a wiki has many benefits: it can be used for ongoing documentation of their work; students can add summaries of their thoughts from the readings, building a collaborative annotated bibliography; it can be used as a presentation tool for the groups' final reports; students in other groups are able to directly comment on and revise the content; it encourages students' authoring practices; and they learn how to produce new knowledge that will be used and developed by others. Furthermore, development of a course-specific wiki enables the design thought process to be captured and made available to current and future students, which is in contrast to the standard format of design courses in which a final report is produced, documenting only the end result of the design process. This paper describes a trial introduction of a wiki in a final year mine design course in order to investigate the applicability of some of these characteristics.

\section{Wiki Technology}

A wiki can be defined as a system that allows one or more people to build up a corpus of knowledge in a set of interlinked web pages [1]. Wikis are simply streams of conversation, revision, amendment, and truncation [2]. The use of a wiki in education is emerging and the use of wiki in educational settings can fall into four main categories [3]:

1. Single-user. A wiki could be used to allow individual students to write and edit their own thoughts and is useful for revision and monitoring changes in understanding over time.

2. Lab book. A wiki can enable students to peer review notes kept online by adding commentary or annotations to class notes, reading, links and discussions.

3. Collaborative writing. A wiki has the potential as a collaborative platform to be used by a team for joint research such as a design engineering group project, writing and preparing an essay or presentation.

4. Creating a topical knowledge repository for a module cohort. The wiki can be used as a repository which is developed through collaborative entries where students can create content that represents their constructed knowledge during the course.

\section{Mine Design Course}

The underground mine design course is a final year design project for mining engineering students at Queen's University. For a number of years, the course has followed the same format: students are provided with a three-dimensional model of metal grades, 
various types of geological and geotechnical information, and a description of the site location.

From this starting point the students are required to complete a feasibility study, which involves a complete mine design and economic analysis. As the capstone design project, the mine design involves integration of many of the skills learned throughout the undergraduate curriculum. Although many previous courses involve a significant design component, this is the first time that the students are faced with such a comprehensive, large scale open ended design challenge. The class is divided into groups of between four and six, depending on the class size, and weekly group meetings are held with the professor to monitor progress and work on design issues. Groups are free to discuss their procedures and results, but due to various assumptions that need to be made during the design process (the data is always incomplete) the designs invariable diverge and groups inevitably have to rely on their own efforts to complete the project.

The marking scheme has been based on group participation, a mid-term progress report, a final report and presentation, plus a peer assessment in which group members have an opportunity to rate the performance of their team members. The assessment is heavily based on what the students have done in their design: the emphasis is on the final product as opposed to the process.

A recurrent difficulty in the design project has been sourcing up-to-date reference material on some of the design procedures, and how to apply those procedures in an integrated design as opposed to stand-alone design calculations. Obtaining cost data for equipment and products plus various mining activities has also been challenging as much of this is tightly held by suppliers in a competitive market. In this way, the project highlights the differences between component knowledge and system integration, the latter of which is a critical skill for engineer to learn. For this, unfortunately, there is little published information in the mining literature: Text-books on mining engineering tend to be introductory, quickly outdated, or too general for a comprehensive design project. Similarly, published case histories tend to emphasize what was done (the final design) as opposed to why it was done (the design thought process), they are usually too site specific, and they often require an amount of data not available to the students or require design expertise or design effort beyond the level expected of students in a single term project.

In the mining industry, the art of mine design is learned through many years of experience by practicing engineers who rely heavily on the expertise of their colleagues or consultants as opposed to written comprehensive design manuals. While this system works well in industry, it poses some difficulties for students attempting their first major design project at a university. A common solution in these circumstances would be for the professor to prepare a suitable manual or guide. However, this would suffer some of the same limitations as currently published material mentioned above.

\section{MineWiki}

The decision to use a wiki for the mine design course (MineWiki) emerged after discussions with Queen's University's engineering librarians who are active participants in assisting professors and students not only with conventional library resources, but in exploring the potential of new technologies in teaching and learning. Through these discussions and after reviewing a number of case studies in using wikis in different engineering and science courses such as the use in software engineering [4] [5], introductory engineering design course [6], information systems [7], mechanical engineering [8], chemical engineering [9], and multidisciplinary and capstone design courses [10] [11]), it was decided that the mine design course would be a good candidate in which to experiment with wikis.

Furthermore, it was decided that for this group of students, which was a particularly large class, the added workload of creating wiki contributions would be the responsibility of the groups and that they would receive a mark based on their contributions.

They are the ones facing the design problem, they are the ones needing to develop skills, and they need guidelines appropriate for their level of effort. The objective was therefore to capture their thought process in a manner that could be made available to each other and to future design groups.

Benefits of the wiki solution were seen to be:

- Being written by the students, the material would be at the appropriate level for students in the final year design course,

- The design process (the why) would be captured in addition to details (the how),

- The information would become available to all groups at approximately two-thirds of the way through the course, and while not ideal, was still considered soon enough for the current class to make use of each other's contributions,

- Should it work, creation of wiki design content would be implemented in future years and the volume of material would not only increase, it would be up-dateable should future groups or the 
professor judge it necessary - it would become a live as opposed to a static document,

- the students, professor, and engineering librarian would all benefit from the experience with the new technology, although each in different ways.

Due to this being the first trial of the wiki as a design instruction tool, only the basic content creation aspects of wiki technology was explored, although the added value of using topic discussion pages, for example, was clearly seen. While these outcomes were desirable during conception, the reality of judged by student performance was somewhat different, as will be described below.

\subsection{Wiki Selection}

There are many available wiki solutions that can be used and the selection of a specific product as a platform for the MineWiki was a major challenge for us at the beginning of this project. WikiMatrix[13] is a wiki based website that lists different wikis and gives the user the option to compare products. The website lists more than 100 products with their features and examples of their current use. The common features of wiki solutions according to Schwartz et al. [14] are source code, wiki management, page formatting, access control, communications, support and advance features.

The selection of a wiki for educational setting was also discussed by Schwartz et al. to have many criteria that include:

- Cost: the cost of acquiring a solution whether it is open-source software or it requires a license to purchase.

- Complexity: availability of online technical support (documentation, manual, FAQs), help by email/ phone/ fax/ online forum, user community, and if the solution is web-hosted or requires downloading and mounting on a web server.

- Control: how the solution provides access control to allow user registration, password protection of core pages, levels of user rights to edit with permissions, security of content and spam control.

- Clarity: solutions have different formats to represent index/ site map, linking content between different wikis, back-linking, history of all versions (revision tracking), page creation or deletion, notification of changes, and if the solution provides different exporting option to word documents or PDF files.

- Common Technical Framework (CTF): browser and cross-platform compatibility, resolution of simultaneous editing conflicts, and backing up the wiki pages.

- Features: solutions provide many different features to allow editing options for users that can include: WYSIWYG (What You See Is What You Get) editing, HTML support, Text editing (italics, font size, colour), image, hyperlinks, multimedia, tables insertion, and the use of RSS feeds.

The selection of a platform for the MineWiki was challenging given the limited time we had before starting the course and the unavailability of a teaching assistant or a dedicated system support for educational technology in the department. Two products were selected as potential solution: MediaWiki ${ }^{\circledR}$ which is a popular solution and Confluence®, a product for which Queen's University has an institutional license. Table 1 provides a comparison between the two products using the previously identified criteria

Table 1: Comparison of MediaWiki ${ }^{\circledR}$ and Confluence ${ }^{\circledR}$

\begin{tabular}{|c|c|c|}
\hline Feature & MediaWiki® & Confluence $®$ \\
\hline Cost & - free/open source & $\begin{array}{l}\text { - institutional } \\
\text { license }\end{array}$ \\
\hline Complexity & $\begin{array}{l}\text { - requires } \\
\text { installation and } \\
\text { hosting on a } \\
\text { server and } \\
\text { support } \\
\end{array}$ & $\begin{array}{l}\text { - hosted and } \\
\text { supported by } \\
\text { university IT } \\
\text { department }\end{array}$ \\
\hline Control & $\begin{array}{l}\text { provides many } \\
\text { tools to register } \\
\text { users with } \\
\text { different } \\
\text { permissions. }\end{array}$ & $\begin{array}{l}\text { - } \text { students can use } \\
\text { their student ID } \\
\text { to log in the } \\
\text { wiki, } \\
\text { permissions are } \\
\text { assigned by the } \\
\text { space } \\
\text { administrator }\end{array}$ \\
\hline Clarity & $\begin{array}{l}\text { - requires basic } \\
\text { HTML } \\
\text { knowledge } \\
\text { - simple interface } \\
\text { as it is the } \\
\text { interface for } \\
\text { Wikipedia }\end{array}$ & $\begin{array}{l}\text { using word } \\
\text { processor like } \\
\text { format for } \\
\text { editing, lack the } \\
\text { features of } \\
\text { creating a table } \\
\text { of content }\end{array}$ \\
\hline $\begin{array}{l}\text { Common } \\
\text { Technical } \\
\text { Framework }\end{array}$ & $\begin{array}{l}\text { compatible with } \\
\text { major browsers, } \\
\text { requires some } \\
\text { configuration at } \\
\text { the server level. }\end{array}$ & $\begin{array}{l}\text { added plug-in } \\
\text { modules and } \\
\text { macros can be } \\
\text { configured by } \\
\text { the site } \\
\text { administrator } \\
\text { upon request or } \\
\text { when needed. }\end{array}$ \\
\hline $\begin{array}{l}\text { Advanced } \\
\text { Features }\end{array}$ & - available & - available \\
\hline
\end{tabular}


Confluence was selected as the MineWiki platform as it was ready to use with the access control and security managed by the university system administrator. A space for the MineWiki was created with administrative privileges for the course instructor and the engineering librarian.

\subsection{MineWiki Implementation}

The student population for the mine design course in winter 2009 consisted of 34 students in their final semester. They were divided into 5 groups, and the total duration of the course was twelve weeks.

A detailed outline of the design course, objectives, and a description of all deliverables was provided to the class on the first day of the course. Since this was the first use of the wiki and the content was non-existent, groups were encouraged to select a topic of their choice. This was permitted as general experience indicated participation was always more enthusiastic if students worked on topics they were interested in. Topic selections and outlines of the proposed contributions were due at the beginning of week four, and uploaded wiki contributions were due at the end of week eight.

There was some debate as to how much information about the wiki or training should be provided to the students. The final decision to specify the outcome and leave the details for the students to discover by themselves was made on the basis that current students are tech-savvy and quite capable of learning how to use software tools of even greater complexity. Also, a quick poll of the class showed that most had used the most famous of all wikis Wikipedia, and were quite familiar with concepts of web pages, hyperlinking and mark-up language. It was stressed that the contents of the submission should be sufficiently detailed that students such as themselves could refer to the wiki contributions and obtain enough information that they could apply it directly to completing useful tasks in the design project. Use of worked examples, spreadsheet calculation attachments, graphics, and extensive referencing to additional resources were encouraged.

Security of online material is always of concern, especially in this case where groups would be obtaining marks for their contributions. As described, the choice of the Confluence platform was made on the basis of greater security and ease of editing. Firstly, access to the site was restricted to members of the design class. Secondly, wiki access for the design groups was restricted to only the pages they created.

The professor and engineering librarian were set as administrators with full access to all system features. While we would always recommend use of such security measures in case challenges about content corruption should occur, it did not appear to be a necessary step considering the way in which the contributions were made, as will be described.

Finally, with regard to marking, the groups were told in advance what the project was worth as a percentage of their course mark. However, it was intended that a portion of this mark would be derived on the basis of a peer evaluation carried out by the students themselves. This technique had been successfully used for a number of years in evaluating the group mark. While the weekly meetings provided some insight for the professor into who was doing the work, the students had far better knowledge. In practice, there was a high level of consistency in student identification of high and low achievers in the groups. It was hoped that this peer-level scrutiny would also encourage a higher level of performance and group competition. Unfortunately, due to some particular curriculum issues that arose during the term, this requirement was relaxed.

\section{Preliminary Findings}

All wiki proposals and contributions were received on time, but the quality of both varied significantly. Criteria used to evaluate the wiki contributions were relatively simple as these had not been discussed in detail with the students in advance:

\section{- Organization \\ - Technical content \\ - Use of wiki techniques \\ - Completeness}

Measured against these criteria, one was rejected as inadequate and had to be resubmitted, and one was truly outstanding. The other three were somewhat disappointing. The submission that was initially rejected was essentially a limited review of one portion of the proposed subject area, presented in a style that would have been more appropriate for a printed submission. The group had clearly not understood the scope of work, taken the time to do the research work, nor become familiar with the presentation differences between (or advantages) of the wiki compared to standard print assignment. On the other hand, the best submission made creative use of mark-up, had extensive linking and navigation aids, and excelled in the other criteria described above.

While there is always a range of quality in student work, to what can these large differences in wiki technology use be attributed? This was clarified using one of the wiki's administrative features. A history of page editing, including the name of the person making the edits, was recorded. An examination of this editing history revealed that 
group activity could be attributed mostly to one person in each group. In no case was there any evidence of collaborative writing, at least not online. Further analysis showed that this pattern was consistent with the way in which the design groups tended to distribute work. Based on evidence collected over a number of years, students in this major design class were encouraged, but also tended to form by themselves, a group management structure. There was generally a strong manager, and multiple tasks, worked on in parallel, were divided amongst the group members. This division of labour was their strategy for dealing with a complex task, which mirrors the way professionals also organize on design projects. The wiki contribution was handled in this same way, with the resulting quality of the submissions more a reflection of the ability of the student assigned as opposed to the ability of the group.

Other outcomes of note: There were no apparent difficulties with using the wiki, or with any of the editing, linking, or with the relatively simple mark-up language. Some students sought advice on the level of complexity of the content, although the final product did not usually follow through on the advice given. The student responsible for the outstanding contribution worked exceptionally hard, and consulted frequently with the professor about wiki organization and how to make use of the new medium.

With regard to the initial intention that the wiki would become a valuable resource for the current and future students, there were mixed results. The level of detail of most contributions and the limited scope of topic, combined with the submission date relative to the timeline of the project meant that the contributions, except for the single outstanding example, were of little use to the other groups. For future use, it was decided to let all contributions stand. The large number of topics still available provides no limitation on students to choose one that suits their interests, and they will serve to illustrate the range of quality (with some discussion to be provided by the professor) as a guide to future groups.

\section{Conclusions and Next Steps}

The paper presents a preliminary finding of an early implementation of the MineWiki to the mine design course students. The preliminary findings in winter 2009 suggested some conclusions and roadmaps for the next year course. The potential role of wiki in students learning was noticed but it requires us to implement the wiki with the framework of constructivist learning by enabling students to reflect on their own learning and comments on other students' contribution as well. Assessment of wiki contribution is essential as some students contributed more than others, the assessment of the contributed content needs clear guidelines; a grading rubric will be developed for the future course and a clear self assessment tool will be given to students individually and for groups.

There are always risks associated with incorporating use of a new technology into the curriculum. This was considered prior to the trial, but the benefits significantly outweighed the potential risks. In this particular case, the professor had the support of an engineering librarian during the early discussion period, during wiki selection, and during course setup. This support greatly diminished the burden for the professor to make this change to the course, and has resulted in a stronger working relationship between faculty and the library staff. It has been decided on the basis of this experience that the wiki trial will be continued in the future, with improvements to be made on the basis of lessons learned. Some of these are:

- The contributions should be done as early as possible so all groups can make use of the knowledge base.

- Very careful screening of the contributions is required or possible providing a short-list of suitable topics for the groups to choose from.

- The variability in quality of contribution was significant. What do we do in future years to maintain integrity of the knowledge base if we are developing it over many years? We recommend keeping everything but perhaps have a ranking of quality so students can see what the level of contribution should be.

- A more detailed marking rubric or wiki contribution guideline will be developed in advance and provided to the students. They will also have access to the developing wiki at the start of the course.

- Peer evaluation is a critical component of their learning process and for the wiki will be mandatory next time.

- Publication of the interim and final reports using the wiki will not be pursued, as current engineering practice still involves production of formal reports, and experience in producing such a large report resulting from this project was seen as an important part of their training.

This paper briefs some of the technological challenges in addition to opportunities that we have faced for using a wiki for this course. We believe that wiki and other social media software have a lot of 
opportunities to be used in engineering courses but adequate planning and design are needed so the learning environment will help to scaffold students' learning experience without creating challenges to them.

\section{References}

[1] T. Franklin and M. Van Harmelen. (2007, Web 2.0 for content for learning and teaching in higher education. JISC Report Available:

http://www.jisc.ac.uk/publications/documents/web2andpoli cyreport.aspx

[2] B. Alexander, "Web 2.0 A new wave of innovation for teaching and learning?" Educause Review, vol. 41, pp. 3244, 2006.

[3] E. Tonkin, "Making the Case for a Wiki," Ariadne, vol. $1,2005$.

[4] J. Chao, "Student project collaboration using wikis," in Proceedings of Software Engineering Education Conference, 2007, pp. 255-261.

[5] S. Minocha and P. G. Thomas, "Collaborative Learning in a Wiki Environment: Experiences from a software engineering course," New Review of Hypermedia and Multimedia, vol. 13, pp. 187-209, 2007.

[6] H. L. Chen, D. Cannon, J. Gabrio, L. Leifer, G. Toye and T. Bailey, "Using wikis and weblogs to support reflective learning in an introductory engineering design course," in Proceeding of ASEE Annual Conference and Exposition, 2005, pp. 15539-15548.
[7] F. Tétard, E. Patokorpi and K. Packalén, "Using wiki to support constructivist learning: A case study in university education settings," in Proceedings of the 42nd Annual Hawaii International Conference on System Sciences, HICSS, 2009,

[8] A. McGaughey and J. Michalek, "Wiki-based learning in the mechanical engineering classroom," in ASEE Annual Conference and Exposition, Conference Proceedings, 2008.

[9] D. Hohne, L. Fu, B. Barkel and P. Woolf, "The wiki approach to teaching: Using student collaboration to create an up-to-date open-source textbook," in ASEE Annual Conference and Exposition, Conference Proceedings, 2007.

[10] K. Racicot and C. Pezeshki, "Assessing group learning using wikis: An application to capstone design," in ASEE Annual Conference and Exposition, Conference Proceedings, 2006.

[11] W. Walter, J. Webb, M. Smith, E. DeBartolo, M. Bailey and G. Slack, "Redesigning a college-wide multidisciplinary engineering design program at RIT," in ASEE Annual Conference and Exposition, Conference Proceedings, 2007.

[12] P. Duffy and A. Bruns, "The use of blogs, wikis and RSS in education: A conversation of possibilities," in Proceedings of the Online Learning and Teaching Conference, 2006, pp. 31-38.

[13] WikiMatrix. [Online]. (June 15, 2009), Available: http://www.wikimatrix.org/

[14] L. Schwartz, S. Clark, M. Cossarin and J. Rudolph, "Educational wikis Features and selection criteria," International Review of Research in Open and Distance Learning, vol. 5, 2004. 